\title{
The Strategic Role of Design in Driving Digital Innovation: A Theoretical Foundation
}

\author{
Zitong $\mathrm{Gao}^{1^{*}}$ and David Hands ${ }^{1}$
}

\begin{abstract}
The emergent theme of design led innovation is well recognized now. Yet, the association between 'design' and 'digital innovation' remains largely under-explored. In order to help enterprises in the pressure of digital environment to better understand the role of design in promoting digital innovation. Based on the literature, this paper explores the unique characteristics of digital innovation from three aspects: content, organization and impact. On this basis, it conduct a systematic analysis for the role of design in digital innovation. The contribution of this paper is to: (1) explore the practice and significance of design in the digital innovation; (2) make guideness to companies and designers who are committed to adding value to their products or business through digital innovation. This paper argue that design has an intensive strategy role in promoting digital innovation in three aspects. The application of design needs to pay more attention to its overall effectiveness.
\end{abstract}

Keywords: design; digital innovation; design and business; strategy

Submitted: May $27^{\text {th }}, 2020$ / Approved: January $11^{\text {th }}, 2021$

\section{Introduction}

According to Schumpeter, society is destroyed every 50 years, with disruptive innovation resulting in industrial revolution (Schumpeter, 1942). The world has seen three such revolutions-from the industrial economy in the late 17 th century to the experience economy based on the second and third industrial revolutions in the 20th century (Duguay, Landry, \& Pasin, 1997). Now, we are in the beginning of the Fourth Industrial Revolution, characterized by both significantly improved abilities of problem-solving and the capacity for changing the world through introducing digital technology across society (Schwab, 2017), which is called knowledge economy (Brand \& Rocchi, 2011). Digitalization is changing the way of creating value (Normann \& Ramirez, 1993). People are now in an era in which significant competitive advantage is achievable digital innovation (Demirkan, Spohrer, \& Welser, 2016). The internet of things (IoT) is the biggest and most anticipated digital trend (Ryan \& Watson, 2017). Based on the Internet platform to develop new products, services, or remake business models become the key for enterprises to seek survival and development (Lamarre \& May, 2019), which is no longer just the business of software companies (Yoo, Boland, Lyytinen \& Majchrzak, 2012). Those who are able to listen, learn, and adapt are likely to be the ultimate winners. Therefore, the huge opportunities make increasing enterprises turn to the Internet for innovation. However, innovation based on digital platforms has new characteristics and requirements that is different from traditional innovation. Uptake of digital innovation is uneven and many organizations are feeling the pressure from digital innovation. In this context, the role of design in promoting innovation has attracted more and more attention and recognition from academia and practice fields. It is beyond the compass of the traditional design framework and links to its context of technology, society, and economy (Liu, Liu, \& Zhang, 2018). There is growing evidence that the role of design has changed to lead innovation activities at the current stage (Acklin, 2010). For enterprises and designers who want to seek digital innovation and gain a place in the increasingly fierce market competition: It is necessary to explore the important role of design in digital innovation, especially based on the Internet. Strive to better understand the complex multidimensional "design" concept of innovation management. This paper will critically examine and debate the following related research questions: First, explore the changing nature of digital innovation, understand its unique characteristics that different from traditional innovation; Secondly, critically analyzes the emergent role of design as well as discusses the possibility of design promoting digital innovation from three levels of digital innovation (Design methods and tools promote innovation of digital content; Design culture and strategy to help organize digital innovation practices; Design creates meaningful digital value). Finally, this paper conclude that design plays a comprehensive and intensive role in digital innovation; To give guidance to the companies who want to start businesses in the digital industry; As well as gives advice on skills preparation and education for future designers.

\section{Digital innovation: A Systemic View}

The concept of digital innovation has been defined in academia from a wide variety of perspectives. The first conceptualization is "information technology (IT) innovation," has been used to refer to the organizational adoption and diffusion of new IT-enabled processes, products, and services (Fichman, 2004; Jeyaraj, Rottman, \& Lacity, 2006). It is more emphasis on the innovation and application of new digital technologies, as well as the integration with physical components of products, to produce new products, new processes or new business models (Fichman, 2004). The second conceptualization is used to refer to a product-centric perspective (Yoo, Henfridsson, \& Lyytinen, 2010), involving new combinations of physical and digital products to form new products. It is related to design but takes a more holistic perspective beyond design science to focus on a wider

(1) Imagination Lab, Lancaster University, United Kingdom

${ }^{*}$ Corresponding author: z.gao5@lancaster.ac.uk 
range of concepts. Fichman, Santos and Zheng (2014) emphasized that enterprises adopting digital innovation need to make major changes in technology, organization and other aspects to adapt to the new development model and lead to new products, services, or processes. In recent years, Ciriello, Richter and Schwabe (2018) identified characteristics of digital technology, suggesting that digital innovation is innovating products, processes, or business models using digital technology platforms as a means or end within and across organizations. For example. Uber is the world's largest taxi company but owns no taxis, instead of location-based services that are completed using cloud-enabled technologies. Consequently, it has changed people's traditional car-hailing approach to taxi usage, as such, now relying on a digital platform to provide new service processes to create meaningful value to their customers.

\section{Digital Innovation: Digital Platforms and Service}

Digital innovation radically transforms the nature of corporate innovation practices. Digital innovation has convergence and generativity (Yoo et al., 2012). Convergence means that the digital technologies combine previously separate components, it is the "ability of different network platforms to carry essentially similar kinds of services"(European Commission, 1997, p. 1); Generativity refers to an ability that innovation subject adapt to the digital trend actively and use digital technology creatively to create new products and services (Zittrain, 2006). Such features make the initial architecture of digital innovation is incomplete and product boundaries are constantly changing (Gawer, 2009). Compared with traditional innovation, which is mostly centred on modularization (Baldwin \& Clark, 2003) and have clear product boundaries and a complete product architecture (Tchertchian, Millet, \& Pialot, 2013). Digital innovation tends to be more efficient and dynamic, and more difficult to control and predict. It requires a deep understanding and ongoing exploration of users based on changing environments and requirements (Yoo, 2012).

Digital innovation with decentralized organization characteristics, need widespread participation and democratization (Ciriello et al., 2018). This is because digital technology reduces the communication cost between organizations, broadens the scope of communication, and promotes the collaboration among heterogeneous innovation participants (Lyytinen, Yoo, \& Boland, 2016). Organizations and innovators are moving from vertical integration to bilateral fragmentation, the innovation track be driven from within the organization to the edge of the enterprise boundary and innovation network (Ciriello et al., 2018). This results in loosely connected networks. The participation of the main body of innovation from the enterprise as the center into a platform of digital product or service as the center and gradually form a more flexible and extensible digital ecosystem (Um, Yoo, Wattal, Kulathinal, \& Zhang, 2013). Most of the Internet SMEs are born into such networks, meaning that they can develop and grow on a massive scale and in unusual ways (Tumbas, Berente, Seidel, \& Brocke, 2015), if and when they draw from capabilities offered by others in the ecosystem (Selander, Henfridsson, \& Svahn, 2013). Nowadays, a large number of Internet companies are relying on mobile operating systems such as iOS (App Store) and Android (Google Play) as application development platforms to realize digital innovation. In this background, when it comes to developing digital innovations, the resulting solutions often embody characteristics of products and services in the same time. Therefore, they are often described as product-service system or service innovation (Matzner, Buttgen, Demirkan, Spohrer, Alter, Fritzsche, \& Neely, 2018). Service innovation is a networked collaborative process of co-creating value enabled by complex socio-technical systems with combinable digital resources (Barrett, Davidson, Prabhu, \& Vargo, 2015). Service-dominant logic perspective gradually replaces product-dominant logic, re-conceptualizes service as the application of specialized knowledge through a process of value co-creation in a network of providers, customers, beneficiaries, and other actors (Vargo \& Lusch, 2008). In this background, strategy is no longer a set of fixed activities along the old industrial model-value chain. Instead, it is trapped in a more complex, multi-industry value system, which is known as 'value constellation' (Speed and Maxwell, 2015). Shown as in Figure1.

Figure1: A value constellation model. Source from Speed and Maxwell, 2015

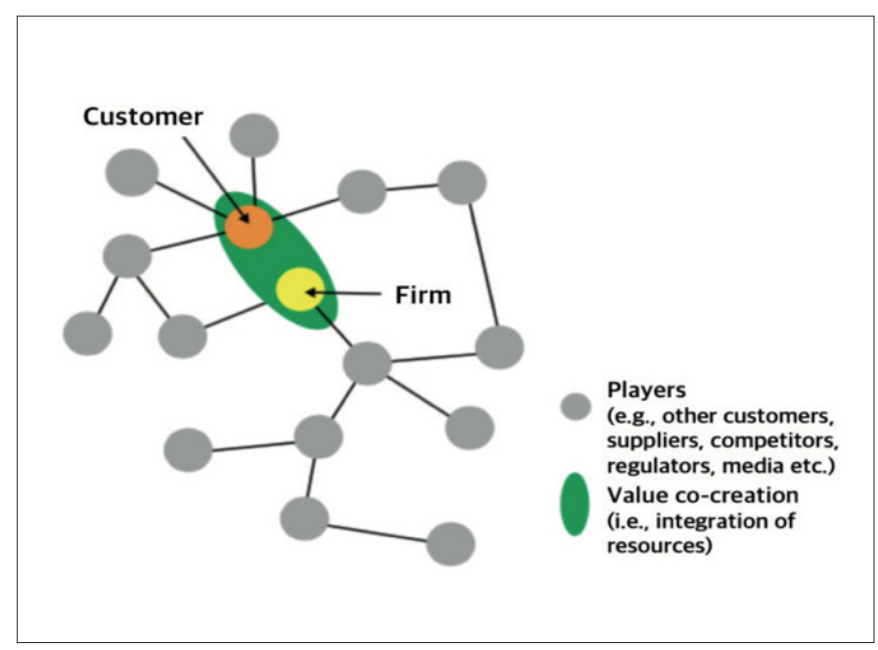

Organization of Digital Innovation: Digital Practices

Under the influence of digital technology, not only the content of digital innovation has changed, but the organization form of digital innovation is also different from the traditional innovation. In general, traditional innovation has often been described as a linear, regular and ordered process. It can be arranged and controlled by developers and each stage is related to its context. For example, Tidd and Bessant(2011) believethat the organizational process of innovation can be planned as search, select, implement, and capture; Desouza's (2011) put forward the innovation process consists of idea generation, advocacy \& screening, experimentation, commercialization, and diffusion \& implementation. And Fichman et al. (2014) distinguish between discovery, development, diffusion, and impact. Although such innovation process is also necessary for digital innovation, they are not enough to improve an organization's ability to conduct digital innovation (Ciriello etc., 2018).

Digital innovation has the characteristics of convergence, generativity, widespread participation, and democratization. Therefore, 
it has many forms of innovation like combinatorial innovation and distributed innovation (Yoo et al. 2012). To achieve these innovation forms and response to the complex nature of digital innovation, the company needs to understand and support those "practices" that actively develop digital innovation (Tuomi, 2002). Therefore, the concept of "digital innovation practice" was put forward. Different from traditional innovation, digital innovation is regarded as a social interactive practice activities without history and future--digital practice, which is programmed, interdependent, goal-oriented and mediated by digital technology (Ciriello, Richter \& Schwabe, 2017). Practice is using human's bodies, brains and physical objects to satisfy their intentions and needs, which is a purposeful and targeted human activity (Kaptelinin and Nardi 2009). In the digital innovation practice, digital coded information needs to be collected and combined across organizational boundaries or directly involved with entrepreneurs (Desouza, 2011) within the organization to generate, develop, and implement ideas for innovative solutions (Yoo etc., 2012; Ciriello etc., 2018). These entrepreneur employees are called intrapreneurs (Desouza 2011, p. 5). Intrapreneurship is a form of direct participation in which the employee takes the initiative to generate, develop, and implement ideas for innovative solutions (Høyrup, Hasse, Bonnafous-Boucher, Møller, Lotz, 2012), which is one of the crucial driver for the development of digital innovations.

\section{Impact of Digital Innovation: Digital Exploration}

In the face of traditional innovation, organizations typically encounter a tension between exploitation (i.e., incrementally improving the existing business) and exploration (i.e., radically innovating in new business areas) (March, 1991). Based on the characteristics of digital innovation, rather than being predictable, focusing on improvement and renovation in more well understood areas, management approaches for digital innovation are exploratory and focus on experimentation (Ciriello etc., 2018). Norman and Ramirez (1993) also pointed out that: Successful companies increasingly do not just add value, they reinvent it.

Base on the high complexity of digital innovation, which is difficult to predict and control. Digital innovation is quite different from traditional innovation from content to process to result. From a systematic perspective, digital innovation is more likely to be carried out under the organization of digital innovation practices by intrapreneurship, so as to realize exploratory innovation with new value (as shown in the Figure 2). Digital innovation is full of challenges and pressures for enterprises. Cross-professional cooperation teams have been called for, but it is very difficult to operate. Doing so effectively requires a holistic, company-wide strategy, coordinate different world views and different terms to co-create new values is becoming an increasing challenge and exploration for organizations in the digital age (Johnson, Christensen \& Kagermann, 2008 ; Stickdorn etc., 2018).

Figure 2: Systemic View of Digital innovation, drawn by Zitong Gao

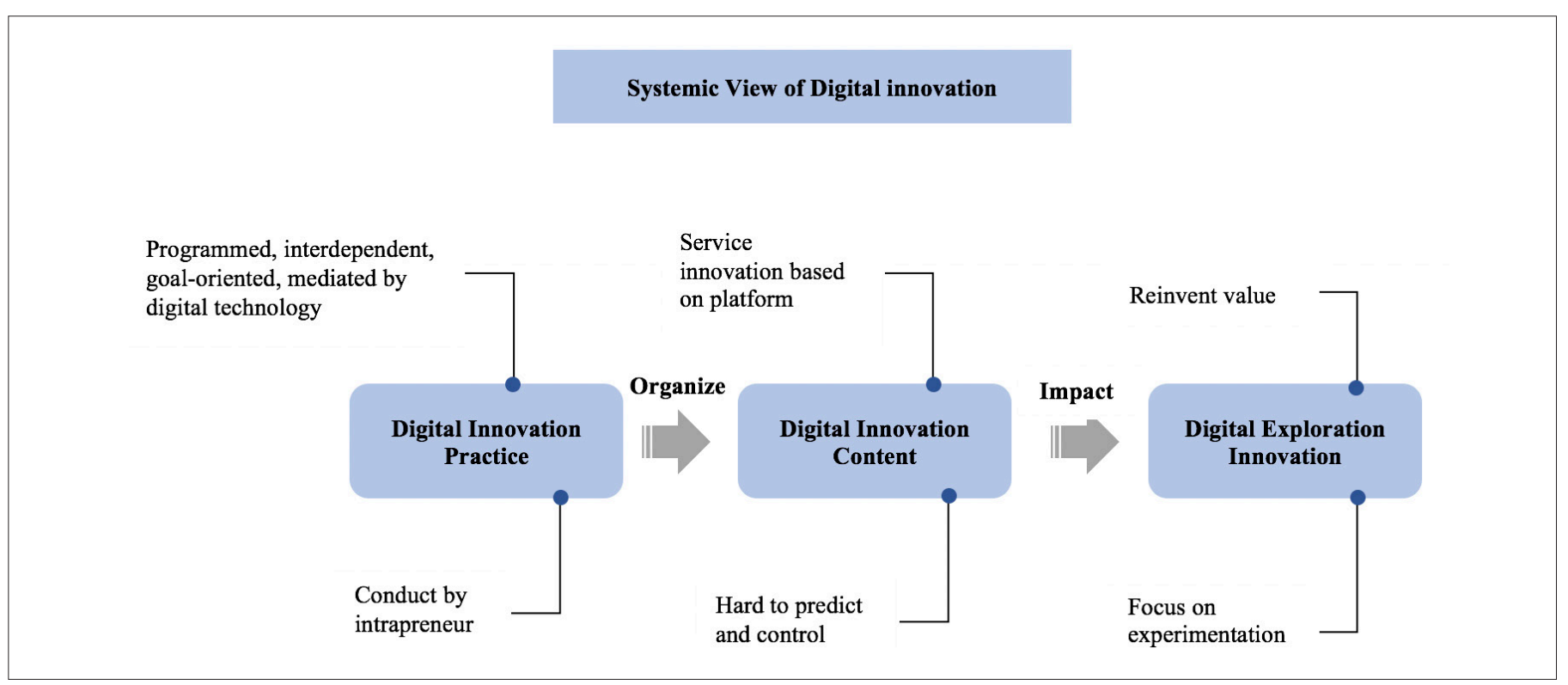

\section{The Emergent Role of Design(ing)}

Design as a broad and complex discipline has a plethora of levels of meaning that its values and roles of have been continually changing over the last decade. Initially, design was regarded as a scientific method aimed at creating new and useful forms or artefacts to give satisfaction, or the imaginative jump from present facts to future possibilities (Archer, 1965; Reswick, 1965; Gregory, 1966; Simon,
1969). Such innovation has more focus on the contribution of design to product appearance and styling (Kotler and Rath, 1984). A series of scholars focused on design as a practical activity to solve problems and understand things (Schön, 1983; Buchanan, 1992; Cross, 1982; Lawson, 2005), they began to focus on exploring design tools that can be used to solve complex management problems and drive innovation, whilst receiving the attention of practitioners and managers alike. After entering the field of management, the concept of 
user-centred "design thinking" popularised by IDEO, first became the portal to promote innovation in the whole design field (Brown, 2008). It is defined as using a designer's sensibility, principles, and methods as tools to discover human needs and combine them with viable technologies and business strategies with the ultimate goal of creating enterprise value and business opportunities through customer value (Ibid, 2008)shown as Figure 3.From this, Design as a strategic tool began to be continuously discussed.

Figure 3: Design thinking. Source from IDEO.

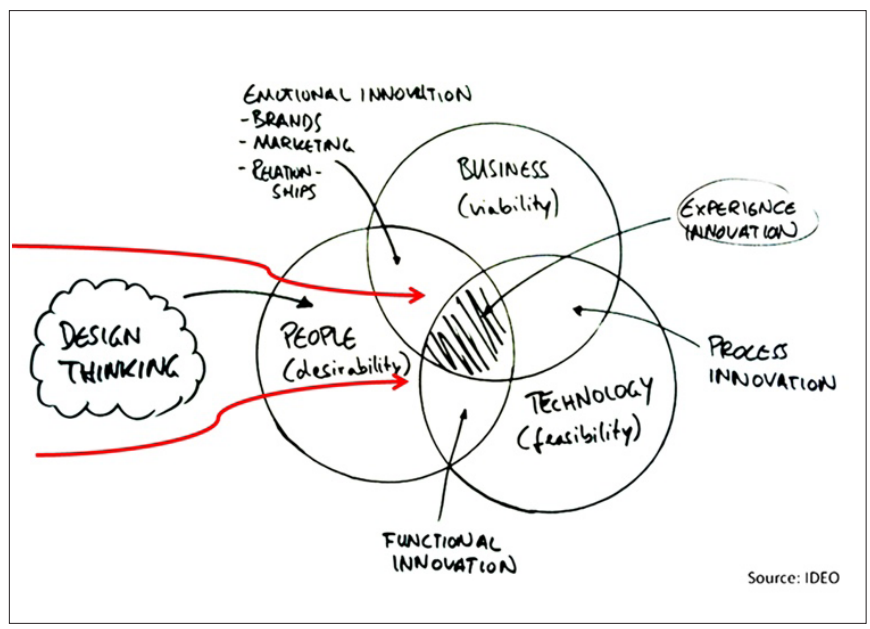

The development of digital technology promotes the economic transformation from industry and experience economy to a knowledge economy (Schwab, 2017). It is not only has transformed ways of creating value but also changed the role of design and the designer (Perks, Cooper \& Jones 2005). In the developed world, this trend has been proven to meet the challenges of the digital revolution in the 2010s. For example, the strategic value of design is presented in the Digital Manufacturing and Design Innovation Institute (DMDII) in the $\mathrm{USA}^{1}$, German Industry $4.0^{2}$, British Industry $2050^{3}$ as well as Made in China $2050^{4}$. All these demonstrate that design is essential to digital creativity. Digital innovation scholars also put forward the role of design in promoting the practice of digital innovation (Ciriello et al., 2018), point out that teams explore user requirements by applying design thinking methods or frameworks (Brown, 2008). It is widely accepted that design thinking can help to quickly understand users and develop prototypes and evaluate with them during the iterative process (Ciriello et al., 2017). However, critics argue that this narrow interpretation of design thinking does not completely cover the role design plays in innovation (Jahnke \& Johansson-Sköldberg, 2014). The role of design in digital innovation should be viewed from a broader holistic perspective.

\section{The Intensive Role of Design in Driving Digital Innovation}

Supported by empirical evidence, more and more people believe that methods and tools such as design thinking have a positive and causal impact on the results of innovation. Case studies of companies adopting design-oriented innovation have highlighted the transformative effects of design-oriented approaches (Martin, 2009; Verganti, 2009).
According to the current studies on design leading innovation in the academic world, the paper argues three aspects of design promoting digital innovation, which correspond to the content level, organizational level and innovation results of digital innovation. These alignments are discussing below:

\section{Design Bring Insight and Landing for Digital Innovation Content (As tools and methods)}

First, the cognitive strategies of design brings insight into digital content. Many scholars view design, and by extension design-led innovation, as underpinned by a set of cognitive strategies. While from the perspective of digital innovation, digital innovation it is centered on digital platform, based on digital infrastructure and driven by data (Ciriello etc., 2018). The initial architecture of digital innovation is incomplete and product boundaries are constantly changing. Digital companies also need to understand the needs of digital users in a timely manner and quickly improve the product and respond to changes in the market. Therefore, digital innovation has no history and no clear future, and it is necessary to constantly seek new possibilities. In the design cognitive strategies, abductive logic is the process of proposing a hypothesis to explain the data, which in design is 'what might be' rather than the current or previous state of affairs (Roozenburg, 1993). 'Predict' the future by re-framing issues and emergent insights that contribute to the real needs of end-users; Airbnb, for example, as the world's largest home rental company that has no housing stock of its own. Base on the digital platform, Airbnb innovate a service that "connects the traveler and the homeowner who has vacant homes for rent." Such innovative idea is produce from the logic of abductive, in which tourists ostensibly want to find a house but actually want to get all kinds of housing informations. Instead of just offering rooms to customers like a normal hotel, Airbnb is rethinking the problem from the root cause. By innovating a platform that connects travelers and hosts to provide users with more diverse accommodation information from all over the world.

Second, in addition to the cognitive approach, design tools like design ethnography (such as interview, observation, tracking, etc.) are also considered to be capable of imagining and presenting new ideas (Brown, 2008) that related to the "of" the abstract domain of the discovery framework. The main body of digital innovation has changed from an enterprise-centered platform to a platform centered on digital products or services, gradually forming a more flexible and extensible digital ecosystem (Ciriello etc., 2018; Yu, Meng, Zhang etc.,2017). Digital innovation focuses more on innovation from products designed for virtual services. Service is around the people's daily life so that high degree of user participation and understanding of user needs are the key to driving innovation. Ethnography is a sociological and anthropological term. Definition of the term ethnography has been subject to controversy and usually refers to forms of social research having a substantial numer of the following features: A strong emphasis on exploring the nature of particular social phenomena; A tendency to work primarily with "unstructured" data; Investigation of a small number of cases; Analysis of data that involves explicit interpretation of the meanings and functions of human actions (Aktinson and Hammersley, 1998). In the broad sense, ethnography is a methodology used to repre- 
sent the perspective of everyday life. Ethnography appeals to designers because it provides a window onto the ways consumers interact with products in their everyday lives. Design ethnography is an emerging discipline that draws on many of the theories,practices, and methodologies of anthropology, as well as other social-science disciplines,such as psychology, sociology, and communications. Design ethnography is based uponunderstanding what people do, what they say,and what they think and focuses on the broad patterns of everyday life that are important and relevant specifically for the conception, design, and development of new products and services (Salvador and Anderson, 1999). Ethnography in the application of design is centered on the study of user behavior, with the field survey as the main method and the purpose of exploring user needs (Wasson, 2000). Designers through field research visit the appropriate "demanders", observing, tracking, interviewing and recording,to try to understand people's way of life and ultimately explaining the unmet and hidden needs of users; In the process of exploring the real needs of users, Airbnb has also made observations on millennial travelers through a large number of observations, interviews and questionnaires. It discovered the major travel groups in the contemporary era and explored the constantly changing travel themes. Through design ethnography, Airbnb drawn persona to defined different travel scenes of different types of people. Thus the systematic design of products and services can be conduct based on user requirments. Until now, Airbnb still release the traveler insight report in every year. Keep an eye on users' changing travel styles, hobbies and needs. Continuously provide and improve the variety of service contents.

Finally, digital prototype testing, storytelling, scenario and other design tools can bring digital innovation to the ground and return to the "concrete domain" to generate the actual solution (Beckman and Barry, 2007). Compared with the traditional innovation based on modularization, digital innovation is more efficient, dynamic and difficult to control. Therefore, organizations must provide appropriate tools to enable the creation and exchange of innovative ideas and to help the early concepts of innovation to be gently translated into a formal development process. Numerous studies have shown that digital prototyping and storytelling can quickly test innovative insights and help to build a common understanding between innovators and users to facilitate communication (Ciriello etc., 2007); In order to verify the innovative content and gain the understanding and recognition of users. After insight into user needs and systematic design, Airbnb hired animators from Disney pixar to demonstrate the scenario storyboard of customer experience. The application of storyboard can not only help Airbnb to check the process and experience of the service before going online, but also help to perceive the service from the perspective of users that find the deficiencies and make the timely improvement. It can also make the digital service easier to be digested and understood by users, as well as help the innovation get rapid recognition when going online.

Different from traditional innovation, digital innovation is hard to predict and needs to constantly explore future possibilities and users' essential needs; Digital innovation is more of a virtual service based on a detailed understanding of users' lives. Digital innovation is difficult to control, and we need to use tools to help the innovation 'gently land'. The application of design methods and tools can serve as a working principle, discovering requirements, generating assumptions, and quickly testing, to form a framework for digital innovation content.

\section{Design Lead the Digital Innovation Practice's Organize (As the culture and strategy)}

From the perspective of innovation's organize, digital innovation is different from the traditional linear process of innovation, which is an exploratory practice activity. It needs to continually innovate with experimentation from intrapreneurs and (extended) innovation teams and wider eco-systems. Altimeter 'The State of Digital Transformation 2019' also illustrates a growing awareness of the importance of human factors central to digital transformation. Examples include employee experience and organizational culture. In design aspect, some scholars put forward that the design research literature downplays the capability of individuals and companies to develop design as a capability (Hobday, Boddington, \& Grantham, 2012). In order to further improve innovation capability and results, many organizations now implement design and design thinking as organizational capabilities (Liedtka, 2011). Therefore, in digital innovation, more attention should be paid to the ability of enterprises and individuals to develop design as a capability. Innovation scholars have identified two types of antecedents: internal organizational factors and individual factors.

On the organizational level, design practices and configuration development are required within the organization before design become the part of the company's business strategy. Leading to significant innovative strategic initiatives, design and design management scholars emphasize the importance of developing projects to improve design and design thinking throughout the organization. Developing design projects helps to embed design into the organization so that corporate culture takes design as its "dominant logic" (Beverland and Farrelly, 2007); Tantan is a stranger social platform based on big data analysis and artificial intelligence matching recommendations. Since its launch, it has become a leader in Chinese dating products. To develop Tantan, the founders built an innovative multi-disciplinary project team including engineers, user experience designers, and others. By designing a new dating path, the team developed a stranger dating product for Chinese users, which is suitable for Chinese social habits and culture. The innovation mode of the company is based on the design project system. After the product of Tantan becomes mature and stable, the company starts to set up other projects, such as a new digital innovation project "Chinese-style online blind date platform" is conducting.

On the individual level, Nigel Cross argued the within his seminal work "Designerly Ways of knowing" (Cross, 1982). These are the ways of knowing and thinking and acting that are inherent in designing. 'Professional and experienced designers' dispositions and strategies include: Thinking at multiple levels of simultaneity (Cross, 1997); Have a systematic approach to solving problems (Cross \& A.C. Cross, 1998); Have deep cultural interests (Strickfaden, Heylighen, Rodgers, \& Neuckermans, 2006); Using design strategy rather than trial and 
error (Kleinsmann, Deken, Dong, \& Lauche, 2012). "Lontong” is a comprehensive online platform integrating food recipe sharing community, e-commerce and content payment. Since its launch, it has been the no. 1 food product in China for many years. Its founder is a designer with nearly ten years of working experience. The reason why the founder decided to make this product at first is also due to his professional habit as a designer, which is to record some problems at any time and think about them. During this insight, he found that as the post-80s and 90s generation began to enter the kitchen, they couldn't cook but were eager to keep learning and experimenting, and more eager to show off. Therefore, the founder raised a question: how to bring new cooking experience to young people and make it easier for young people who love cooking to learn to cook. Under the leadership of founder that have "Designerly Ways of knowing", the team systematically connected the two processes of learning and sharing to create a "community of sharing cooking skills", which subverted the traditional way of learning to cook and solved the initial problems raised by the founder.

Digital innovation is an exploratory practice that requires continuous innovation through experiments with intrapreneurs and (extended) innovation teams as well as broader ecosystems. It is necessary to carry out digital innovation practice projects under the leadership of internal professional designers or leaders with designer thinking. To implement design and design thinking as organizational capabilities, so as to effectively support the smooth development of digital innovation practice.

\section{Design Creates Meaningful Value}

In 2005, Krippendorff defined design as creating meaning from a philosophical and semantic context (rather than artefacts In Simon's concept). In recent years, this view is combined with business to define the new role of design to inspire innovation (Krippendorff, 2005). Verganti (2009) proposed design-driven innovation that as a search for new meaning, which focuses on why consumers use a particular product, rather than what the product is or how it is used. The concept of meaning refers to what values a product creates for a consumer, including psychological, emotional, utilitarian and socio-cultural values (Verganti, 2009). This provides an alternative strategy for companies to develop products that are more valuable. In the process of digital innovation, its exploratory demand coincides with the concept of design-driven meaningful innovation. To generate valuable ideas that may be transformed into a product or service innovation is consistently a top priority for Internet companies. Whether it is Airbnb, Tantan, Lontong, are all innovated the platform and service that have new meaning. Instead of just offering rooms to customers like a normal hotel, Airbnb innovated a subversive house rental service; Tantan went deep into Chinese social culture and redefines Chinese strangers' online social contact, so that Chinese people who are afraid to start a pick-up line can simply expand their social circle; Instead of offering training or recipe introductions for users who want to learn how to cook, Lontong created a food sharing platform where everyone is equal in it and can share the recipe to each other.
At the same time, according to Verganti (ibid, 2009), the purpose of design-driven innovation is to produce new frames for products and services, and these new frames in turn create opportunities for innovations (Ibid, 2009). Digital innovation also needs continuous iteration innovation to improve product boundaries, as well as stimulate the ability of enterprises to carry out continuous innovation spontaneously. Based on the new concept, all three companies have continued to innovate through data and feedback: Airbnb began to try to carry out room design and life experience plan; Tantan innovates a range of value-added businesses; Lontong innovates "bazaar" as a commercial platform.

We can find that innovations based on digital platforms have brought new value to users and changed people's way of life. At the same time, design-driven innovation creates a basic framework for digital products and services. Based on the new digital meaning, the company can constantly improve the product framework, create new digital opportunities, as well as stimulate the ability of enterprises to carry out sustainable digital innovation spontaneously.

\section{Conclusions}

Based on the analysis of different aspects of the content, practice and impact of digital innovation, it can be found that under the background and influence of digital technology, there are many differences between digital innovation and traditional innovation forms. Digital innovation is harder to predict and inherently more complex, requiring constant refinement of an initially incomplete product framework. Digital innovation is more of a virtual service base on the digital platform, and created from a detailed understanding of users's life. Digital innovation is an exploratory practice that requires continuous innovation through experimentation with intrapreneurs, (extended) innovation teams and broader ecosystems. Design plays an increasingly intensive role in driving digital innovation. The application of design needs to pay more attention to its overall effectiveness to help enterprises achieve strategic and systematic growth. To be successful in digital business, this process and vision need to be carefully planned and managed. In the increasingly competitive digital environment, the exploratory demand of digital innovation requires enterprises and designers to pay more attention to the value of meaningful innovation in design; Design will be an important tool and method to gain insight into the possibilities and facilitate the gentle landing of ideas, helping to face complex challenges and macro uncertainties; The application of design will comes not only from the outside, but also more from the internal strategy and culture of an alive start-up. As a result, design will become a holistic company-wide strategy that coordinate different world views and different terms to co-create new digital value. Not only that, it will have a huge impact on future design education, especially on the skills preparation and learning of the new generation of designers in the coming decades. However, further research and discussions are still needed in the future as to whether design is the most critical and decisive factor in digital innovation, as well as whether its role and performance in different types and sizes of enterprises are consistent. 


\section{Notes}

1. The goal of the U.S. digital manufacturing and design innovation (DMDI) institute is to establish a national institution focused on complex problems in the U.S. manufacturing sector and to develop solutions to offset the risks of U.S. manufacturing companies adopting these new technologies and thereby improve their competitiveness.

2. Industry 4.0 is one of the 10 «future projects» identified by the German government. As part of the high-tech 2020 strategic action plan, it aims to build Germany into a leading supplier and market.

3. On 30th October 2013, the UK government's office of science and the department for business, innovation and skills released the vision project: a long-term vision of UK manufacturing from now to 2050. https://www.gov.uk/government/publications/ future-of-manufacturing

4. This is a roadmap for China to improve its innovation and manufacturing capabilities in 20 years. The concept of innovative design is put forward: Innovation Design is a creative integrated innovation and activity. Facing the knowledge economy, it targets industries with the characteristics of green, intelligent network, coordination, and co-creation and sharing. It enables radical innovation of technology, process, management, and business model through integrating with science and technology, arts and culture, and business based on user-centred design. Innovation design includes various design fields, such as engineering design, industrial design, service design, etc. and combines them with a systematic thinking.

\section{References}

Acklin, C. (2010). Design-Driven Innovation Process Model. Design Management Journal, 5(1), 50-60.

Aktinson, P., \& Hammersley, M. (1998). Ethnography and participant observation. Strategies of Qualitative Inquiry. Thousand Oaks: Sage, 248-261.

Archer, L. B. (1965). Systematic Method for Designers, Council of Industrial Design.

Baldwin, C. Y., \& Clark, K. B. (2003). Managing in an age of modularity. Managing in the modular age: Architectures, networks, and organizations, 149, 84-93.

Barrett M, Davidson E, Prabhu J, Vargo SL (2015) Service innovation in the digital age: key contributions and future directions. MIS Q 39(1):135-154

Beckman, S. L., \& Barry, M. (2007). Innovation as a learning process: Embedding design thinking. California management review, 50(1), 25-56.
Beverland M , Farrelly F J . What Does It Mean to Be Design-led?[J]. Design Management Review, 2007, 18(4).

Brand, R., \& Rocchi, S. (2011). Rethinking value in a changing landscape. A model for strategic reflection and business transformation. Eindhoven: Philips Design.

Brown, T. (2008). Design Thinking. Harv Bus Rev June 2008:84- 95

Buchanan, R. (1992). Wicked problems in design thinking. Design issues, $8(2)$, 5-21.

Ciriello, R. F., Richter, A., \& Schwabe, G. (2017, May). When prototyping meets storytelling: practices and malpractices in innovating software firms. In 2017 IEEE/ACM 39th International Conference on Software Engineering: Software Engineering in Practice Track (ICSESEIP) (pp. 163-172). IEEE.

Ciriello, R. F., Richter, A., \& Schwabe, G. (2018). Digital Innovation. Business \& Information Systems Engineering, 60(6), 563-569.

Cross, N. (1982). Designerly ways of knowing. Design studies, 3(4), 221-227.

Cross, N. (1997). Creativity in design: analyzing and modeling the creative leap, In Leonardo. p. 311-31.

Cross, N. and A.C. Cross (1998). Expertise in engineering design, Research in Engineering Design. vol. 10, no. 3 pp 141-149.

Demirkan, H., Spohrer, J. C., \& Welser, J. J. (2016). Digital innovation and strategic transformation. IT Professional, 18(6), 14-18.

Desouza KC (2011). Intrapreneurship: managing ideas within your organization. University of Toronto Press, Toronto

Duguay, C. R., Landry, S., \& Pasin, F. (1997). From mass production to flexible/agile production. International Journal of Operations \& Production Management.

European Commission (1997). 'Green Paper on the Convergence of the Telecommunications, Media and Information Technology Sectors, and the Implications for Regulation. Towards an Information Society Approach', COM (97)623, Brussels 3 December 1997, (http:// www.ispo.cec.be/convergencegp/).

Fichman, R. G. (2004). Going beyond the dominant paradigm for information technology innovation research: Emerging concepts and methods. Journal of the association for information systems, 5(8), 11.

Fichman, R. G., Dos Santos, B. L., \& Zheng, Z. (2014). Digital innovation as a fundamental and powerful concept in the information systems curriculum. MIS quarterly, 38(2), 329-A15.

Gawer, A. (2009). Platform dynamics and strategies: from products to services. Platforms, markets and innovation, 45, 57. 
Gregory, S. A. (1966). Design science. In The design method (pp. 323330). Springer, Boston, MA.

Hobday, M., A. Boddington, and A. Grantham (2012) An Innovation Perspective on Design: Part 2, Design Issues. vol. 28, no. 1 pp 18-29.

Høyrup, S., Bonnafous-Boucher, M., Hasse, C., Møller, K., \& Lotz, M. (Eds.). (2012). Employee-driven innovation: A new approach. Palgrave Macmillan.

Jahnke, M., \& Johansson-Sköldberg, U. (2014). Introducting designdriven innovation: A challenging ride towards new possibilities. $\mathrm{Mi}$ llennial spring: Designing the future of organizations, 165-190.

Jeyaraj, A., Rottman, J. W., \& Lacity, M. C. (2006). A review of the predictors, linkages, and biases in IT innovation adoption research. Journal of information technology, 21(1), 1-23.

Johnson, M. W., Christensen, C. M., \& Kagermann, H. (2008). Reinventing your business model. Harvard business review, 86(12), 57-68.

Kaptelinin V, Nardi BA (2009) Acting with technology: activity theory and interaction design. MIT Press, Cambridge

Kleinsmann, M., Deken, F., Dong, A., \& Lauche, K. (2012). Development of design collaboration skills. Journal of Engineering Design, 23(7), 485-506.

Kotler, P. and Rath, A.G. (1984), "Design: a powerful but neglected strategic tool”, Journal of Business Strategy, Vol. 5(5, pp. 16-21.

Krippendorff, K. (2005). The semantic turn: A new foundation for design. CRC Press.

Lamarre, E., \& May, B. (2019). Ten trends shaping the Internet of Things business landscape. Retrieved from https://www.mckinsey. com/business-functions/digital-mckinsey/our-insights/ten-trendsshaping-the-internet-of-things-business-landscape

Lawson, B. (2005). How designers think: The design process demystified. Burlington, MA.

Liedtka, J. (2011) Learning to use design thinking tools for successful innovation, Strategy \& Leadership. vol. 39, no. 5 pp 13-19.

Liu, S. X., Liu, H., \& Zhang, Y. (2018). The new role of design in innovation: A policy perspective from China. The Design Journal, 21(1), 37-58.

Lyytinen, K., Yoo, Y., \& Boland Jr, R. J. (2016). Digital product innovation within four classes of innovation networks.

March, J. G. (1991). Exploration and exploitation in organizational learning. Organization science, 2(1), 71-87.

Martin, R.L. (2009) The Design of Business: Why Design Thinking is the Next Competitive Advantage, Harvard Business School Press, Cambridge, MA.
Matzner, M., Büttgen, M., Demirkan, H., Spohrer, J., Alter, S., Fritzsche, A., \& Neely, A. (2018). Digital transformation in service management.

Normann, R., \& Ramirez, R. (1993). From value chain to value constellation: Designing interactive strategy. Harvard business review, 71(4), 65-77.

Perks, H., Cooper, R., \& Jones, C. (2005). Characterizing the role of design in new product development: An empirically derived taxonomy. Journal of product innovation management, 22(2), 111-127.

Reswick, J. B. (1965). Prospectus for an engineering design center. Cleveland, $\mathrm{OH}$ : Case Institute of Technology.

Roozenburg NF.On the pattern of reasoning in innovative design[J]. Design Studies.1993 Jan 1;14(1):4-18.

Ryan, P., \& Watson, R. (2017). Research challenges for the Internet of Things: what role can OR play? Systems, 5(1), 24.

Salvador, T., Bell, G., \& Anderson, K. (1999). Design ethnography. Design Management Journal (Former Series), 10(4), 35-41.

Schön, D. A. (1983). The reflective practitioner how professionals think in action.

Schumpeter, J. (1942). Creative destruction. Capitalism, socialism and democracy, 825, 82-85.

Schwab, K. (2017). The fourth industrial revolution. Crown Business.

Selander, L., Henfridsson, O., \& Svahn, F. (2013). Capability search and redeem across digital ecosystems. Journal of information technology, 28(3), 183-197.

Simon, H. A. (1969). The sciences of the artificial. Cambridge, MA.

Speed, C., \& Maxwell, D. (2015). Designing through value constellations. interactions, 22(5), 38-43.

Strickfaden, M., Heylighen, A., Rodgers, P., \& Neuckermans, H. (2006). Untangling the culture medium of student designers. CoDesign, 2(02), 97-107.

Stickdorn, M., Hormess, M. E., Lawrence, A., \& Schneider, J. (2018). This Is Service Design Doing: Applying Service Design Thinking in the Real World. "O’Reilly Media, Inc..

Tchertchian, N., Millet, D., \& Pialot, O. (2013). Modifying module boundaries to design remanufacturable products: the modular grouping explorer tool. Journal of Engineering Design, 24(8), 546-574.

The State of Digital Transformation 2019. (2020). Retrieved 13 March 2020, from https://www.prophet.com/download/the-state-of-digitaltransformation/ 
Tidd J, Bessant J (2011) Managing innovation: integrating technological, market and organizational change. Wiley, Hoboken

Tumbas, S., Berente, N., Seidel, S., \& vom Brocke, J. (2015). The 'digital façade 'of rapidly growing entrepreneurial organizations.

Tuomi I (2002) Networks of innovation. Oxford University Press, Oxford

Um, S., Yoo, Y., Wattal, S., Kulathinal, R., \& Zhang, B. (2013). The architecture of generativity in a digital ecosystem: a network biology perspective.

Verganti, R. (2009). Design driven innovation: changing the rules of competition by radically innovating what things mean. Harvard $\mathrm{Bu}-$ siness Press.
Wasson, C. (2000). Ethnography in the field of design. Human organization, 377-388.

Yoo, Y. (2012). The tables have turned: How can the information systems field contribute to technology and innovation management research. Journal of the association for information systems, 14(5), 4.

Yoo, Y., Boland Jr, R. J., Lyytinen, K., \& Majchrzak, A. (2012). Organizing for innovation in the digitized world. Organization science, 23(5), 1398-1408.

Yoo, Y., Henfridsson, O., \& Lyytinen, K. (2010). Research commentary-the new organizing logic of digital innovation: an agenda for information systems research. Information systems research, 21(4), 724-735.

Zittrain, J. L. (2006). The Generative Internet, 119 Harvard Law Review 1974. 